\title{
Tovaria pendula Ruiz \& Pav., (Tovariaceae), nueva especie, género y familia para Nicaragua
}

\author{
Dania L. Paguaga R. ${ }^{1^{*}}$
}

1. Universidad Nacional Autónoma de Nicaragua, León (UNAN-LEÓN). Facultad de Ciencias y Tecnología, Departamento de Biología, Herbario Miguel Ramírez Goyena “HULE”, León, Nicaragua. Tel: (505) 2311 5013, ext: 1136.

\section{RESUMEN}

Se describe e ilustra la especie Tovaria pendula Ruiz \& Pav., que representa un nuevo registro para la flora de Nicaragua. La familia Tovariaceae, está representada por el género Tovaria, el cual es de amplia distribución en América Tropical, pero en las Antillas se conoce únicamente de Jamaica. En Nicaragua fue colectada por primera vez en la montaña Cerro de Jesús, municipio de Jalapa, departamento de Nueva Segovia, a una altitud de 1400 a 1500 m, en las coordenadas 1358'37' N, 86¹0'29'W, durante una evaluación florística rápida.

Palabras claves: Tovariaceae, especie, género, Jalapa, Nicaragua.

\section{INTRODUCCIÓN}

En Nicaragua fue recientemente colectada la especie Tovaria pendula Ruiz \& Pav. lo que representa una nueva adición a nivel de familia, género y especie para el país. La Familia Tovariaceae está representada por hierbas o arbustos a veces escandentes, con un solo género monotípico, Tovaria, el cual está ampliamente distribuido en América tropical, pero en las Antillas solamente se conoce de Jamaica.

Tovaria pendula Ruiz \& Pav., se colectó como parte de una evaluación florística realizada en La Hacienda Jesús Mountain ubicada a unos ocho kilómetros del valle de Jalapa, Nueva Segovia, localizada en el borde de la frontera con Honduras en las coordenadas $13^{\circ}$ $58^{\prime} 50^{\prime \prime} \mathrm{N} ; 86^{\circ} 10^{\prime} 54^{\prime \prime}$ con una altura máxima de 1720 msnm.

Esta especie, es rara, crece en sitios alterados, en elevaciones medias y altas, distribuida desde México a Sudamérica y Jamaica. Es importante mencionar que la montaña Cerro de Jesús, es una zona que esta dedicada al cultivo de café y esta habitada principalmente por trabajadores de la hacienda y unas pocas personas nativas del lugar que están vendiendo sus tierras para cultivos de café.

Tovaria pendula, se colectó subiendo sobre la trocha principal, después del vivero Caturra, creciendo a la orilla del camino, dentro del área de cultivo de café, no se colectó de otro sitio dentro de la reserva y aun no se han reportado otras colectas en el país. El bosque en el cerro se encuentra por encima de los $1300 \mathrm{msnm}$, debajo de esta altura la vegetación se compone principalmente de cafetales y algunos árboles que han quedado del bosque primario que aún son utilizados como sombra de este cultivo, entre los cafetales predominan las plantas del género Inga y frutales como los Citrus. En la nebliselva del cerro de Jesús es muy abundante la planta endémica Hoffmannia gesnerioides y otras especies que solamente se conocían de una colección en Nicaragua, como Smilax velutina.

\section{DISEÑO METODOLÓGICO}

La Hacienda Jesús Mountain, tiene una área total de 600 hectáreas, de las cuales cerca de la mitad son de bosque primario, predominando el bosque de nebliselva, que se encuentra por encima de los $1300 \mathrm{~m}$, debajo de esta altura la vegetación se compone principalmente de cafetales y algunos árboles que quedaron del bosque primario que aún son utilizados como sombra para café.

Se realizó una Evaluación Florística en la Hacienda Jesus Mountain o Montaña de Jesús en Jalapa Nueva Segovia, en Julio del 2006, se hicieron recorridos por los principales senderos de la hacienda, para cubrir de esta manera los diferentes ambientes presentes en el área. Las muestras botánicas colectadas fueron de más o menos $30 \mathrm{~cm}$ de largo con flores y/o frutos, las que se colocaron en bolsas plásticas y se les aplicó alcohol al $90 \%$, para ser trasladas al Herbario de la UNANLeón (HULE), donde fueron secadas a $70^{\circ} \mathrm{C}$ por cinco días, luego fueron identificadas, utilizando, la Flora de Nicaragua y otras Floras regionales.

Posteriormente a la identificación realizada en el Herbario HULE, el material botánico se trasladó al Herbario del Jardin Botánico de Missouri, para realizar la determinación cruzada por un especialista en la familia. 


\section{RESULTADOS Y DISCUSIÓN}

\section{Descripción taxonómica}

La familia Tovariaceae esta constituida por hierbas o arbustos, a veces escandentes, glabros, muy aromáticos; produciendo plantas hermafroditas. Las hojas son alternas, trifoliadas y sin estípulas. Inflorescencias en racimos alargados, terminales, flores actinomorfas pequeñas, abrazadas por brácteas lanceoladas; sépalos (6-) 8 (9), libres, imbricados y deciduos; pétalos (6-) 8 (9), sésiles; estambres (6-) 8 (9), insertos en el disco nectarífero; ovario globoso, cortamente estipitado a casi sésil, 6-8-carpelar, óvulos numerosos, campilótropos, estilo corto o ausente, estigmas $6-8$, cortos, sésiles o casi sésiles. Fruto una baya globosa, estigmas persistentes; semillas numerosas con el embrión encorvado y rodeado por endosperma aceitoso. Esta ampliamente distribuida en América tropical, pero en las Antillas solamente se conoce de Jamaica y esta representada por un solo género monotípico, Tovaria, el cual tiene dos especies en America Tropical. La familia está estrechamente relacionada con Capparaceae pero se diferencia de ésta por el endosperma bien desarrollado, la placentación axilar y mayor número de sépalos, pétalos y carpelos. ${ }^{[1,2]}$ (figura 1)

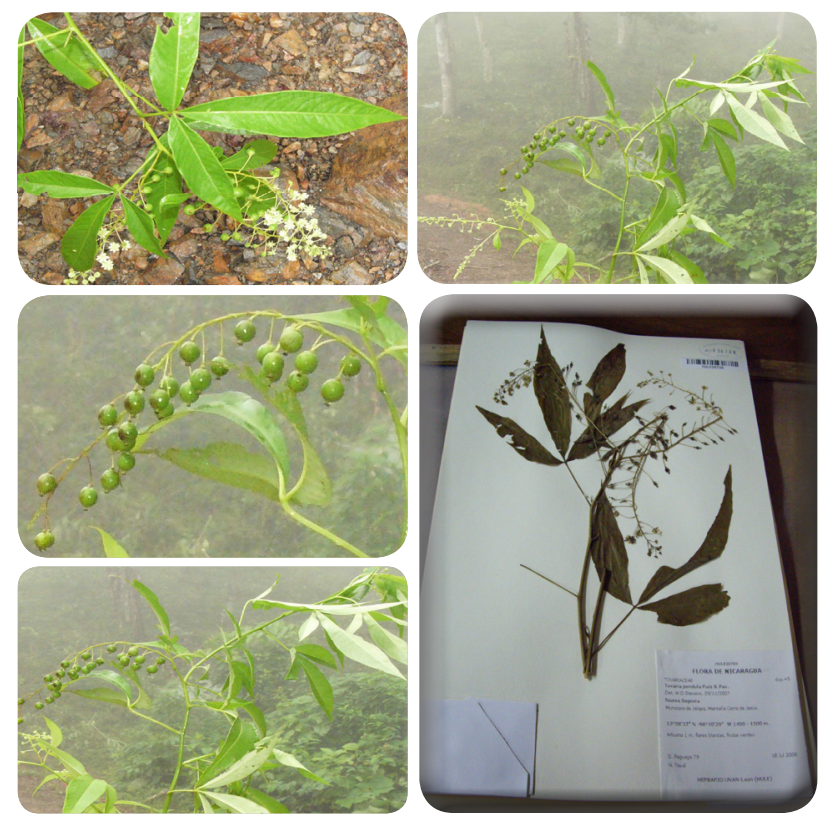

Figura 1. Fotografías de muestras de material botánico recolectado de la especie Tovaria pendula Ruiz \& Pav.
El genero monotípico Tovaria esta constituido por dos especies en América Tropical. Tovaria había sido incluido en Capparaceae, pero muchos autores están de acuerdo que debería tratarse como una familia separada. La embriología, morfología del polen, el gran numero de pétalos, sépalos y carpelos son características que son utilizadas para considerarlo muy cercano a Capparaceae, ambas familias se encuentran en el mismo orden.

Sin embargo, Tovaria difiere de la mayoría de las Capparaceae por tener un endosperma bien desarrollado y especialmente el ovario plurilocular con placentación axilar. El endosperma de las semillas y la placentación axilar son evidencias primitivas, pero el número de sépalos, pétalos y carpelos puede reflejar una segunda aparición. ${ }^{[1,2]}$

La especie Tovaria pendula Ruiz \& Pav., crece como hierbas, arbustos o raramente árboles, hasta $1.5 \mathrm{~m}$ de alto. Hojas con 3 folíolos lanceolados a lanceoladoovados, el folíolo central más grande, usualmente $7-13 \mathrm{~cm}$ de largo y $1.5-5 \mathrm{~cm}$ de ancho, ápice agudo a largamente acuminado, base obtusa, márgenes enteros; pecíolo $2.5-5.5 \mathrm{~cm}$ de largo. Flores en racimos laxos, hasta $30 \mathrm{~cm}$ de largo o raramente más largos, verdes o amarillos a blancos; sépalos lanceolados, 3-5 mm de largo; pétalos más o menos elípti-cos, 3-7 $\mathrm{mm}$ de largo; filamentos ca $1 \mathrm{~mm}$ de largo, aplanados, anteras 1-2 mm de largo; ovario globoso, 1-locular pero parcialmente dividido, estigmas $6-8$. Fruto $1-1.5 \mathrm{~cm}$ de ancho.

Diagnóstico: Arbustos hasta $1.5 \mathrm{~m}$ de alto, hojas alternas trifolioladas, inflorescencia en racimo terminal, péndulo, alargado, flores amarillentas o verdosas. ${ }^{[3,4]}$

La especie es común desde México hasta Sudamérica y Jamaica. En Nicaragua se colecta y se reporta por primera vez en el Cerro de Jesús, ubicado a 8 kilómetros del municipio de Jalapa Nueva Segovia, el 18 de Julio, 2006. La muestra se colectó de un arbusto de $1 \mathrm{~m}$ de alto, flores blancas y frutos verdes inmaduros, la cual en una primera revisión fue identificada como Forchhammeria trifoliata Radlk. (Capparaceae), especie con la que esta cercanamente emparentada, pero se diferencian por que Tovariaceae tiene el endosperma bien desarrollado, la placentación es axilar y tiene un mayor número de sépalos, pétalos y carpelos, la corteza y los frutos tienen savia amarilla. Posteriormente la planta fue determinada como Tovaria pendula en la identificación cruzada realizada en el Jardín Botánico de Missouri en el año 2007. 


\section{CONCLUSIONES}

Se reporta una nueva especie para Nicaragua, que representa además un nuevo género y nueva familia para la flora del país. Este hallazgo demuestra que todavía faltan muchas especies que agregar a la ya alta diversidad de esta área ubicada en el centro de América Central.

\section{AGRADECIMIENTOS}

A Paul Kirk de la Universidad de Chico, California, apoyo la gira de campo a El Cerro de Jesús, Nelson Toval acompaño a la gira de campo y tomo las fotos de este material, W.D. Stevens (MO) identifico el material botánico y Ricardo Rueda reviso este articulo.

\section{REFERENCIAS BIBLIOGRAFICAS}

1. Miller, J.S., 2001. Tovariaceae. Flora de Nicaragua, Monograph 85, Vol III. Missouri Botanical Garden Press.

2. http://www.efloras.org/florataxon.aspx?flora id=201\&taxon_id=133187

3. http://www.illustratedgarden.org/mobot/rarebooks/ page. asp? relation=QK253R98317981802V3\&ident ifier $=0313$

4. http://mobot.mobot.org/cgi-bin/search_vast 